\title{
Mapping the Gene Causing X-Linked Recessive Nephrolithiasis to Xp11.22 by Linkage Studies
}

\author{
S. J. Scheinman, ${ }^{*}$ M. A. Pook, ${ }^{\star}$ Carol Wooding, ${ }^{\star}$ J. T. Pang, ${ }^{*}$ P. A. Frymoyer, ${ }^{\star}$ and R. V. Thakker ${ }^{*}$ \\ * Medical Research Council Molecular Medicine Group, Royal Postgraduate Medical School, Hammersmith Hospital, London W12 \\ ONN, United Kingdom; and ${ }^{\ddagger}$ Department of Medicine, State University of New York Health Science Center, Syracuse, New York 13210
}

\begin{abstract}
$\mathrm{X}$-linked recessive nephrolithiasis is associated with kidney stones and renal tubular dysfunction in childhood progressing to renal failure in adulthood. The primary defect causing this renal tubular disorder is unknown and determining the chromosomal location of the mutant gene would represent an important step toward defining the biochemical basis. We have performed linkage studies in 102 members (10 affected males, 47 unaffected males, 15 obligate heterozygote females, and 30 unaffected females) from five generations of one family. As genetic markers we used 10 cloned human $X$ chromosome fragments identifying restriction fragment length polymorphisms and seven pairs of oligonucleotide primers identifying microsatellite polymorphisms. Linkage with the locus DXS255 was established with a peak LOD score $=5.91$ at $3.6 \%$ recombination, thereby localizing the $\mathrm{X}$-linked recessive nephrolithiasis gene to the pericentromeric region of the short arm of the $X$ chromosome (Xp11.22). Multilocus analysis indicated that the mutant gene was distal to DXS255 but proximal to the Duchenne muscular dystrophy locus on $X p$. Thus, the gene that causes $X$-linked recessive nephrolithiasis maps to the pericentromeric region of the short arm of the $X$ chromosome (Xp11.22), and further characterization of this gene will help to elucidate the factors controlling renal tubular function and mineral homeostasis. (J. Clin. Invest. 1993. 91:2351-2357.) Key words: $X$-linked recessive nephrolithiasis • Fanconi syndrome $\bullet$ DNA linkage studies
\end{abstract}

\section{Introduction}

Hereditary nephrolithiasis with renal failure has recently been reported to occur as an $\mathrm{X}$-linked recessive disorder in one large kindred from northern New York (1). The disease occurred in males only, who suffered from nephrolithiasis, proteinuria, and renal tubular dysfunction in childhood, and from nephrocalcinosis and renal failure in early adulthood. The renal tubular dysfunction had similarities to the Fanconi syndrome (2) and was characterized by kaliuresis, phosphaturia, hypercalciuria, uricosuria, glycosuria, aminoaciduria, and an impaired ability to concentrate urine. However, a comparison of the

Address correspondence to Dr. R. V. Thakker, Medical Research Council Molecular Medicine Group, Royal Postgraduate Medical School, Hammersmith Hospital, Du Cane Road, London W12 ONN, United Kingdom.

Received for publication 18 September 1992 and in revised form 19 January 1993.

J. Clin. Invest.

(c) The American Society for Clinical Investigation, Inc. 0021-9738/93/06/2351/07 \$2.00

Volume 91, June 1993, 2351-2357 clinical features of $X$-linked recessive nephrolithiasis (XRN) ${ }^{1}$ to those of other $\mathrm{X}$-linked renal disorders revealed important differences (1). For example, patients with XRN did not suffer from the ocular and cerebral manifestations associated with the Lowe syndrome (3), which is the only other reported X-linked Fanconi syndrome $(4,5)$. In addition, patients with XRN did not suffer from deafness and the glomerular basement membrane splitting characteristic of Alport's syndrome (6), which is also an X-linked disorder (7) associated with renal failure. The primary pathogenic abnormality causing the renal tubular dysfunction of XRN is unknown. As a step towards elucidating the molecular pathology of this disorder we have performed linkage studies in this family from northern New York, and have localized the mutant gene causing XRN to the pericentromeric region of the short arm of the $X$ chromosome (Xp11.22).

\section{Methods}

Patients. 102 living members from five generations of the previously described family (1) with XRN were investigated. The phenotype of XRN in these family members was established by the finding of nephrolithiasis or hematuria, together with proteinuria and either renal insufficiency or renal tubular dysfunction, e.g., glycosuria, a concentrating defect or increased excretion of potassium, phosphate, calcium, urate, or amino acids. These criteria established the presence of the disorder only in males. Following the previous report (1), an additional four males, who are individuals III.15, V.1, V.6, and VI.1 in Fig. 1 , were found to have XRN. Individual III.15, who is $70 \mathrm{y}$ old, has nephrolithiasis, proteinuria, and renal tubular dysfunction; individuals V.1, V.6, and VI.1, who are, respectively, $18 \mathrm{yr}, 32 \mathrm{mo}$, and $6 \mathrm{yr}$ old, have not been documented to have nephrolithiasis but have the urinary abnormalities associated with XRN. Thus, it was possible to diagnose XRN in males during early childhood (1), which allowed the allocation of affected or unaffected phenotypes. No female met the criteria for XRN and all females therefore were assigned an unaffected phenotype. However, a female was classified as a carrier of XRN if males in subsequent generations manifested the disease or if she was the daughter of an affected male. Thus, the 102 family members included: 10 affected males; 47 unaffected males (including 7 spouses of female carriers); 15 female carriers; and 30 unaffected females.

Genetic markers. Two types of genetic markers were used to maximise the yield of information obtained from the study of polymorphisms in this single family. Thus, RFLPs were detected by the use of cloned human X-chromosome fragments (5), and polymorphisms due to length variations in microsatellite tandem repetitive sequences $(8,9)$ for example of the dinucleotide cytosine-adenine, were detected by the use of flanking oligonucleotide primers and the PCR. Informed consent, as approved by the Institutional Review Board for the Protection of Human Subjects of the SUNY Health Science Center, was obtained before venesection. Venous blood samples were collected in tubes containing EDTA $(0.5 \mathrm{M}, \mathrm{pH} 8.0)$ and kept frozen at $-70^{\circ} \mathrm{C}$. Leukocyte

1. Abbreviations used in this paper: $\mathrm{XRN}, \mathrm{X}$-linked recessive nephrolithiasis; OCRL, oculocerebrorenal. 
III

IV

V

VI

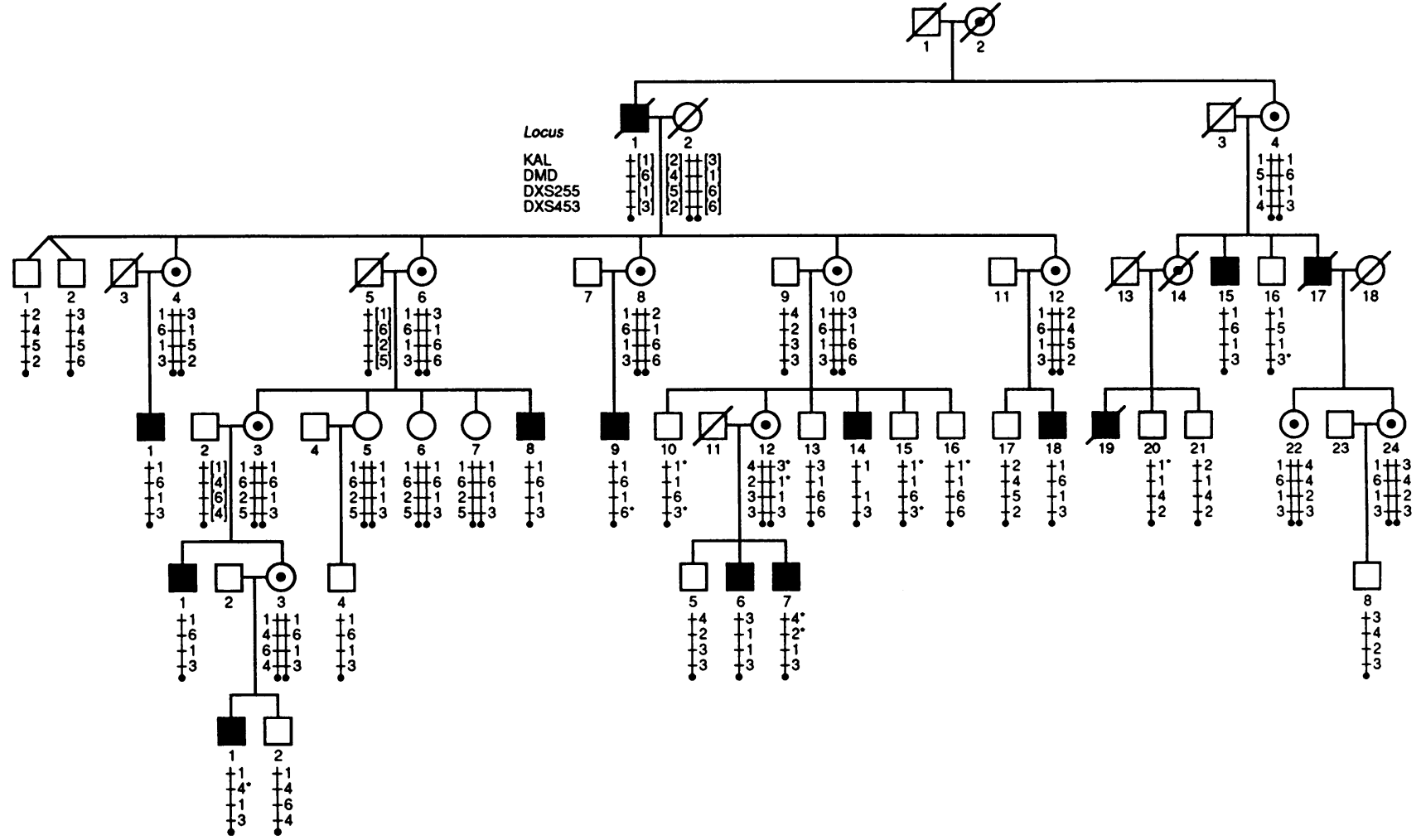

Figure 1. Pedigree from the family segregating for X-linked recessive nephrolithiasis and the short arm polymorphic loci KAL, DMD, DXS255, and DXS453. The pedigree shown has been truncated and the numerals identifying individuals have been altered from the original description (1) to illustrate those family members that yield information for the localization of XRN. The respective alleles for each of the loci, which are shown in the correct order but not the correct distances apart, are indicated by numbers. Individuals are represented as: unaffected male ( $\square$ ), affected male $(\bullet)$, unaffected female $(\circ)$, and carrier female $(\odot)$. In some females the inheritance of paternal and maternal alleles can be ascertained, and in these the paternal X chromosome is shown on the left. Deduced genotypes are shown in brackets. The disease (XRN) is segregating with the haplotype $(1,6,1,3)$ defined, respectively, by the loci KAL, DMD, DXS255, and DXS453, e.g., in individuals III.15, IV.1, IV.8, IV.18, and V.1. Recombinants between XRN and each allele are indicated by an asterisk. Subjects III.8 and IV.12 are carrier mothers who are heterozygous for KAL, DMD, and DXS255; in addition, subject III.8 is also heterozygous for DXS453. The affected son IV.9 is recombinant for the proximal locus DXS453 but nonrecombinant for DXS255, DMD, and KAL. The affected son V.7 is recombinant for the distal loci KAL and DMD but nonrecombinant for DXS255 and DXS453. Additional recombinants involving KAL, DMD, and DXS453 are observed in other members. Recombination involving DXS255 and XRN is indicated by the observation of the affected haplotype $(1,6,1,3)$ in the unaffected male V.4. The minimum number of total recombinants in the pedigree shown is obtained by locating XRN between DMD and DXS255.

DNA was prepared by standard methods $(10)$ and utilized to detect these two types of genetic polymorphisms.

DNA hybridization analysis for RFLPs. $5 \mu \mathrm{g}$ DNA was digested to completion with a fourfold excess of an appropriate restriction enzyme, electrophoresed, and transferred to a nylon membrane (Hybond-N; Amersham Corp., Arlington Heights, IL) by Southern blotting (11) as previously described (12). DNA probes were labeled with the use of $\alpha-{ }^{32} \mathrm{P}$ dCTP by oligonucleotide-primed synthesis (13). A total of 10 cloned DNA probes from the $\mathrm{X}$-chromosome were used in the linkage studies (Fig. 2). The Southern blot was hybridized as previously described (12) and autoradiography with dual intensifying screens and preflashed Fuji medical $\mathrm{x}$-ray film was performed at $-70^{\circ} \mathrm{C}$ for $1-5 \mathrm{~d}$ to reveal the restriction fragment length polymorphisms.

Microsatellite polymorphisms. A total of seven loci-revealing microsatellite polymorphisms from the $\mathrm{X}$ chromosome were used in linkage studies (Fig. 2). Three of these loci (KAL [14], DMD [15], and DXS453 [16]) were from the short arm and four others (DXS3 [17], DXS456 [18], DXS424 [19], and HPRT [20]) were from the long arm. Oligonucleotide primers, $\mathrm{L}$ and $\mathrm{R}$ ( Table I), flanking each microsatellite were synthesized to enable amplification by the PCR of the tandem repeat. $50 \mathrm{pmol}$ of primer $\mathrm{L}$ were 5 '-labeled by the use of $20 \mathrm{U}$ of the enzyme T4 polynucleotide kinase, T4PNK (BRL, Gaithersburg,
MD) in a 25- $\mu$ l vol containing $50 \mathrm{mM}$ Tris- $\mathrm{HCl} \mathrm{pH} \mathrm{7.5,} 10 \mathrm{mM} \mathrm{MgCl}_{2}$, $5 \mathrm{mM}$ dithiothreitol, and $10 \mu \mathrm{Ci}$ of $\gamma^{32} \mathrm{P}$ ATP. PCR amplification was performed by adding $250 \mathrm{ng}$ of genomic DNA to a $25-\mu \mathrm{l}$ vol containing $5 \mathrm{pmol}$ of $\gamma^{32} \mathrm{P}$ end-labeled primer $\mathrm{L}, 5 \mathrm{pmol}$ of unlabeled primer $\mathrm{R}, 50$ $\mathrm{mM} \mathrm{KCl}, 10 \mathrm{mM}$ Tris- $\mathrm{HCl}$ pH 8.4, $2.5 \mathrm{mM} \mathrm{MgCl}_{2}, 0.1 \%$ WI nonionic detergent (BRL), $1.5 \mathrm{U}$ of heat-stable DNA polymerase of Thermus aquaticus (Taq polymerase; BRL) and $0.2 \mathrm{mM}$ of each of dATP, dCTP, dTTP, and dGTP. After an initial denaturation for $1 \mathrm{~min}$ at $94^{\circ} \mathrm{C}, 21-25$ cycles (Table I) of PCR amplification were performed. Each cycle consisted of: $30 \mathrm{~s}$ at $94^{\circ} \mathrm{C}$ to denature double-stranded DNA; $60 \mathrm{~s}$ at $55^{\circ} \mathrm{C}$ to $62^{\circ} \mathrm{C}$ (Table I) for primers $\mathrm{L}$ and $\mathrm{R}$ to anneal to their respective complementary sequences; and $45 \mathrm{~s}$ at $72^{\circ} \mathrm{C}$ for the extension of the DNA strands. These conditions were further modified for the use of the DMD primers as previously described (15). At the end of the $21-25$ cycles, a period of $10 \mathrm{~min}$ at $72^{\circ} \mathrm{C}$ was allowed for extension of the DNA strands. $4 \mu \mathrm{l}$ of the PCR product was electrophoresed on $6 \%$ denaturing polyacrylamide gels at $20 \mathrm{~mA}$ for $5 \mathrm{~h}$. The microsatellite polymorphisms were detected by autoradiography with dual intensifying screens and Fuji medical $x$-ray films at $-70^{\circ} \mathrm{C}$.

Somatic cell hybrids. Rodent-human hybrid cells, which contained a fragment of the human $\mathrm{X}$ chromosome as the only human $\mathrm{X}$ chromosome component, were used for further regional localization of the 


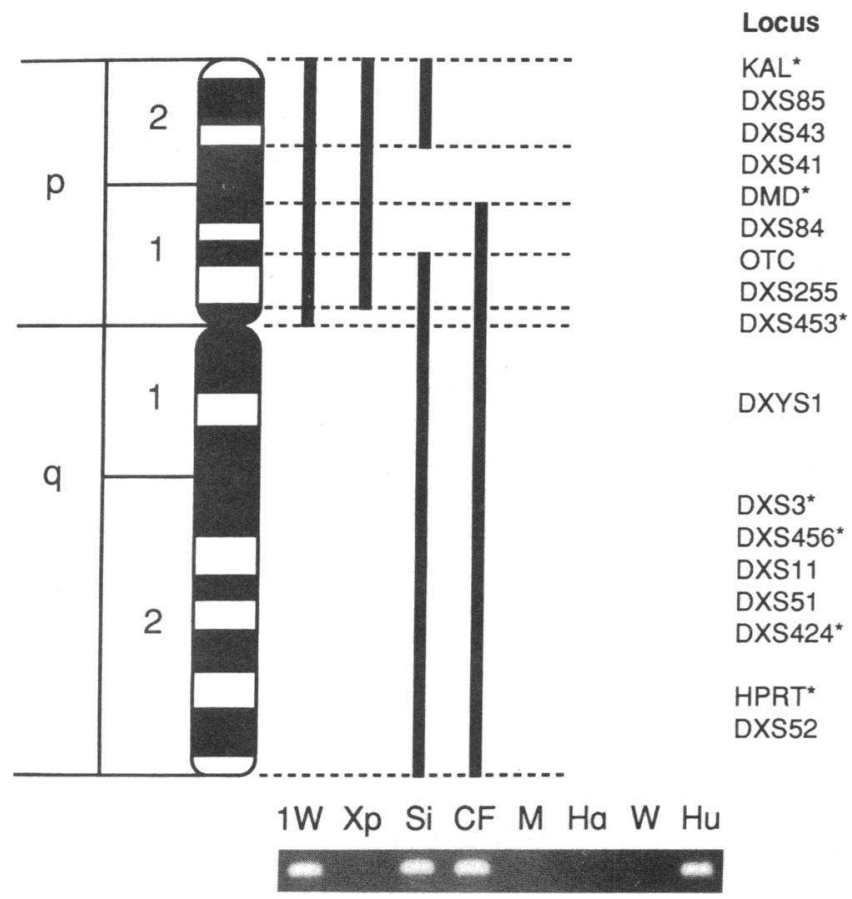

Figure 2. Schematic diagram of a panel of four rodent-human somatic hybrid cell lines containing fragments of the human $\mathrm{X}$ chromosome, which is represented with Giemsa bands. The fragment of the human $\mathrm{X}$ chromosome contained in each hybrid cell line is shown by the solid vertical bar and the name of each hybrid cell line is shown below. $1 \mathrm{~W}$ refers to the cell line 1W1LA4.9, Xp refers to the cell line 835, Si refers to the cell line SIN176, and CF to the cell line CF37. The polymorphic DNA loci are shown juxtaposed to their region of origin on the short (p) and long (q) arms of the X chromosome. The DXS453 locus was localized to Xcen by using specific primers (Table I) and DNA from the rodent-human hybrid cells in PCR amplifications. The PCR products were analyzed by electrophoresis on a $2 \%$ agarose gel stained with ethidium bromide to enable visualization of the DNA fragments which are shown in the lower panel with the respective hybrid cell line or control ( $M$, mouse DNA; $H a$, hamster DNA; $H u$, human DNA; and $W$, water blank) above. The polymorphic DNA loci were used as genetic markers in linkage studies of the family affected with $\mathrm{X}$-linked recessive nephrolithiasis. These polymorphic loci were revealed either by DNA probes identifying RFLPs or by oligonucleotide PCR primers ( $\left.{ }^{*}\right)$ identifying microsatellite polymorphisms. The DNA probes of unknown function have been assigned numbers, e.g., DXS3 to DXS456, and the DNA probes of known function have been allocated gene symbols; for example, the genes encoding Kallmann's syndrome, Duchenne muscular dystrophy, ornithine carbamoyl transferase, and hypoxanthine phosphoribosyl transferase have been assigned the symbols KAL, DMD, OTC, and HPRT, respectively. Linkage between XRN and the DXS255 locus was established, thereby mapping XRN to the pericentromeric region of the short arm of the $\mathrm{X}$ chromosome (Xp11.22).

polymorphic DXS453 locus which had previously been localized to the region Xp11.23-q21.1 (16). The panel of rodent-human hybrid cell lines (Fig. 2) consisted of the human-mouse hybrid cell line IW1LA4.9 which contains Xcen-Xpter $(21,22)$ (V. van Heyningen, personal communication), the human-hamster hybrid cell line 835 which contains Xp (23), the human-hamster hybrid cell line SIN176 which contains the whole human $\mathrm{X}$ chromosome except Xp22.11p11.23 (24), and the human-mouse hybrid cell line CF37 which contains Xp21-Xqter (25). 250 ng of DNA from each rodent-human hybrid cell line was utilized in 30 cycles of PCR amplifications, in which unlabeled oligonucleotide primers $\mathrm{L}$ and $\mathrm{R}$ for the DXS453 locus ( Ta- ble I) were used under the conditions described above. On completion, the PCR amplification products were analyzed by electrophoresis on a $2 \%$ agarose gel stained with ethidium bromide to reveal the DNA fragments under ultraviolet light.

Linkage analysis. The LINKAGE computer programs, version 5.1, were used to analyze the results on a 64 megabyte RAM Sun 4-90 computer running Sun OS4.1.1. Conventional two-point LOD scores were computed for linkage between XRN and each genetic marker with the use of the MLINK and ILINK programs (26) and multipoint location scores were computed using the LINKMAP program (27) as described previously (28). The fixed framework of markers required for multilocus linkage analysis was deduced from previously published genetic maps (29-32). A LOD score of +3 was taken to establish linkage between two loci. The frequency of XRN was taken as $10^{-4}$. Varying the frequency of the disease had no effect on the results of the linkage analysis. The estimates used for the restriction fragment length polymorphism and microsatellite polymorphism allele frequencies have been previously reported (33). The penetrance of the mutant XRN gene has not been established. However, in keeping with $X$ linked recessive disorders $(3,4,5,7,28)$ the disease phenotype could be established in early childhood in males but not females, who undergo $\mathrm{X}$-chromosome inactivation $(4,5,28)$. Thus, males could be allocated affected and unaffected phenotypes but females were all allocated an unaffected phenotype. To assess the effects of an incorrect allocation of the unaffected phenotype we performed separate linkage analyses in which unaffected individuals were reclassified as unknown phenotypes. This excluded these individuals from analysis at the disease locus but enabled use to be made of the X-linked genetic marker data for the purposes of deducing haplotypes. Linkage analysis was thus performed in three separate ways: $(a)$ with males classified either as affected or unaffected and all females classified as unaffected; $(b)$ with the males classified as either affected or unaffected and the females classified as unknown phenotype; and $(c)$ with the unaffected males and females classified as unknown phenotype.

\section{Results}

The inheritance of XRN in the 102 members of the family was consistent with that of an $\mathrm{X}$-linked recessive disorder, as previously described (1). The family proved informative for $10 \mathrm{X}$ linked genetic markers, four from the short arm and six from the long arm, and the results of two-point linkage analysis, in which males were allocated an affected or unaffected phenotype and all females were allocated an unaffected phenotype, are shown in Table II. Linkage between XRN and the DXS255 locus was established with a peak LOD score of 5.91, a recombination fraction $(\theta)$ of 0.036 , and a $95 \%$ confidence interval of 0.001 to 0.180 , thereby localizing XRN to the pericentromeric region of the short arm of the X chromosome (Xp11.22). All the other X-linked RFLP loci gave negative or low LOD scores. To assess the effects of an incorrect allocation of the unaffected phenotype, the peak LOD scores were also calculated using unknown phenotype allocations for these individuals. Varying the phenotype of the females from an unaffected to an unknown phenotype had no effect on the values of the LOD scores in Table II. An additional change in the assignment of the phenotype of males from unaffected to unknown, thereby restricting the analysis to affected individuals only, reduced the LOD scores. However, the LOD score for linkage between XRN and the DXS255 locus remained significant at 3.81 with $\theta=0.000$ and a $95 \%$ confidence interval of 0.000 to 0.153 . These results strengthened the mapping of XRN to Xp11.22, and therefore the genetic map around the XRN locus was studied by defining the position of genetic markers, e.g. DXS453, to 
Table I. Oligonucleotide Primers and PCR Conditions Used To Detect Microsatellite Polymorphisms

\begin{tabular}{|c|c|c|c|}
\hline Locus $^{\text {ref }}$ & Primer sequence & Annealing temperature & Cycles \\
\hline \multirow[t]{2}{*}{$\mathrm{KAL}^{14}$} & L: 5'-CCCAAAGTAAGGATTTTGCCAC-3' & $56^{\circ} \mathrm{C}$ & 21 \\
\hline & R: 5'-TAGATCCTATTTGCCAATTTTTG-3' & & \\
\hline \multirow[t]{2}{*}{ DMD $(44)^{15}$} & L: 5'-TCCAACATTGGAAATCACATTTCAA-3' & $62^{\circ} \mathrm{C}$ & 25 \\
\hline & R: 5'-TCATCACAAATAGATGTTTCACAG-3' & & \\
\hline \multirow[t]{2}{*}{$\operatorname{DMD}(49)^{15}$} & L: 5'-CGTTTACCAGCTCAAAATCTCAAC-3' & $62^{\circ} \mathrm{C}$ & 25 \\
\hline & R: 5'-CATATGATACGATTCGTGTTTTGC-3' & & \\
\hline \multirow[t]{2}{*}{ DXS453 ${ }^{16}$} & L: 5'-GCCCCTACCTTGGCTAGTTA-3' & $55^{\circ} \mathrm{C}$ & 23 \\
\hline & R: 5'-AACCTCAGCTTATACCCAAG-3' & & \\
\hline \multirow[t]{2}{*}{$\mathrm{DXS} 3^{17}$} & L: 5'-AATACATAGGTGTATTGTGACC-3' & $55^{\circ} \mathrm{C}$ & 22 \\
\hline & R: 5'-CCACCTCTCTGAAAGTGTGT-3' & & \\
\hline \multirow[t]{2}{*}{ DXS456 $6^{18}$} & L: 5'-TAACTACACATGTGATTCTG-3' & $55^{\circ} \mathrm{C}$ & 22 \\
\hline & R: 5'-TAAAGATAGAGTGACTGATG-3' & & \\
\hline \multirow[t]{2}{*}{ DXS424 ${ }^{19}$} & L: 5'-CCCAGTTACTAACATCTATG-3' & $55^{\circ} \mathrm{C}$ & 22 \\
\hline & R: 5'-ACCTAGTTGGAGGCTATGCA-3' & & \\
\hline \multirow[t]{2}{*}{ HPRT $^{20}$} & L: 5'-TCTCTATTTCCATCTCTGTCTCC-3' & $55^{\circ} \mathrm{C}$ & 22 \\
\hline & R: 5'-TCACCCCTGTCTATGGTCTCG-3' & & \\
\hline
\end{tabular}

this region and by an analysis of recombinants in the family with XRN.

The regional localization of DXS453 to the pericentromeric region of Xp helped further to study recombinations in this region. The DXS453 locus had previously been localized to the region Xp11.23-q21 (16), and our results helped to refine this localization of DXS453 to Xcen. The oligonucleotide primers for the DXS453 locus yielded PCR-amplified products from human DNA but not from mouse or Chinese hamster DNA (Fig. 2). In addition, PCR-amplified products were obtained from the cell lines 1W1LA4.9, CF37, and SIN176, which contained, respectively, the human $\mathrm{X}$ chromosome fragments Xcen-Xpter, Xp21-Xqter, and an X chromosome which was deleted for Xp22.11-p11.23. No PCR product was obtained from the hybrid cell line containing Xp. These observations localized DXS453 to the centromeric region (Xcen), and this provided a useful highly polymorphic genetic marker for this region.

An analysis of recombination events involving the short arm of the X chromosome helped further to localize the XRN locus. The pedigree in Fig. 1 shows 58 members ( 45 surviving and 13 deceased) in six generations with genetic marker data. The pedigree is informative for the four polymorphic X-linked loci, whose order has been established as Xpter-KAL-DMDDXS255-DXS453-Xcen, and multipoint crosses exist. Individual V.3 is a carrier mother who is heterozygous for DMD, DXS255, and DXS453, and the alleles segregating with the disease can be ascertained by examination of her affected brother's (V.1), affected uncle's (IV.8) and her mother's (IV.3) genotypes. The disease (XRN) is segregating with the alleles $(1,6,1,3)$ defined, respectively, by the polymorphic loci KAL, DMD, DXS255, and DXS453. Her affected son, VI.1, reveals segregation of XRN with the proximal loci DXS255 and DXS453, but demonstrates recombination between XRN and the distal locus DMD. This observation locates XRN proximal to the DMD locus. Analysis of the other branches of the family reveals further recombination between XRN and the short arm loci. For example, the affected male IV.9 is recombinant for XRN and the proximal locus DXS453, and the affected male V.7 is recombinant for XRN and the distal loci $\mathrm{KAL}$ and DMD. The combined observations of multipoint crossovers from these affected males and additional unaffected

Table II. LOD Scores for Linkage of X-linked Markers and XRN

\begin{tabular}{|c|c|c|c|c|c|c|c|c|c|c|c|c|c|c|}
\hline \multirow[b]{2}{*}{ Locus } & \multirow[b]{2}{*}{ Probe } & \multicolumn{2}{|c|}{ Peak } & \multicolumn{11}{|c|}{ LOD scores $\mathrm{Z}(\theta)$} \\
\hline & & $Z(\bar{\theta})$ & $\theta$ & $\mathrm{Z}(0.001)$ & $\mathrm{Z}(0.01)$ & $\mathrm{Z}(0.05)$ & $\mathrm{Z}(0.10)$ & $\mathrm{Z}(0.15)$ & $\mathrm{Z}(0.20)$ & $\mathrm{Z}(0.25)$ & $\mathrm{Z}(0.30)$ & $\mathrm{Z}(0.35)$ & $Z(0.40)$ & $Z(0.45)$ \\
\hline KAL & KAL PCR 1.1/1.2 & 0.33 & 0.354 & -13.08 & -7.11 & -3.07 & -1.47 & -0.65 & -0.17 & -0.12 & 0.28 & 0.33 & 0.30 & 0.18 \\
\hline DMD & $3^{\prime} \mathrm{CA}-\mathrm{F} / \mathrm{R}$ & 2.58 & 0.157 & -4.58 & -0.67 & 1.73 & 2.42 & 2.58 & 2.51 & 2.31 & 2.00 & 1.61 & 1.15 & 0.61 \\
\hline DXS255 & $\mathbf{M} 27 \beta$ & 5.91 & 0.036 & 4.76 & 5.66 & 5.88 & 5.57 & 5.10 & 4.55 & 3.94 & 3.27 & 2.55 & 1.77 & 0.92 \\
\hline DXS453 & Mfd66CA/GT & 1.60 & 0.211 & -7.89 & -2.98 & -0.11 & 1.11 & 1.48 & 1.59 & 1.56 & 1.42 & 1.19 & 0.88 & 0.48 \\
\hline DXS3 & DXS3-1A/B & 0.42 & 0.304 & -9.99 & -5.04 & -1.80 & -0.61 & -0.06 & 0.23 & 0.38 & 0.42 & 0.39 & 0.31 & 0.18 \\
\hline DXS456 & XG30BL/R & 0.05 & 0.431 & -16.45 & -9.45 & -4.59 & -2.61 & -1.55 & -0.90 & -0.47 & -0.20 & -0.04 & 0.04 & 0.05 \\
\hline DXS11 & $\mathrm{p} 22.33$ & 0.03 & 0.661 & -2.34 & -1.34 & -0.68 & -0.41 & -0.28 & -0.19 & -0.13 & -0.09 & -0.06 & -0.04 & -0.02 \\
\hline DXS424 & $849 / 850$ & 0.74 & 0.140 & -0.99 & -0.02 & 0.57 & 0.72 & 0.74 & 0.71 & 0.64 & 0.55 & 0.44 & 0.31 & 0.16 \\
\hline HPRT & HPRT PCR 2.1/2.2 & 0.36 & 0.259 & -3.70 & -1.72 & -0.43 & -0.03 & 0.24 & 0.33 & 0.36 & 0.35 & 0.31 & 0.23 & 0.13 \\
\hline DXS52 & St14 & 0.24 & 0.335 & -8.36 & -4.40 & -1.76 & -0.77 & -0.28 & 0.00 & 0.16 & 0.23 & 0.24 & 0.20 & 0.12 \\
\hline
\end{tabular}

Phenotype classification: males affected or unaffected; females all unaffected. 


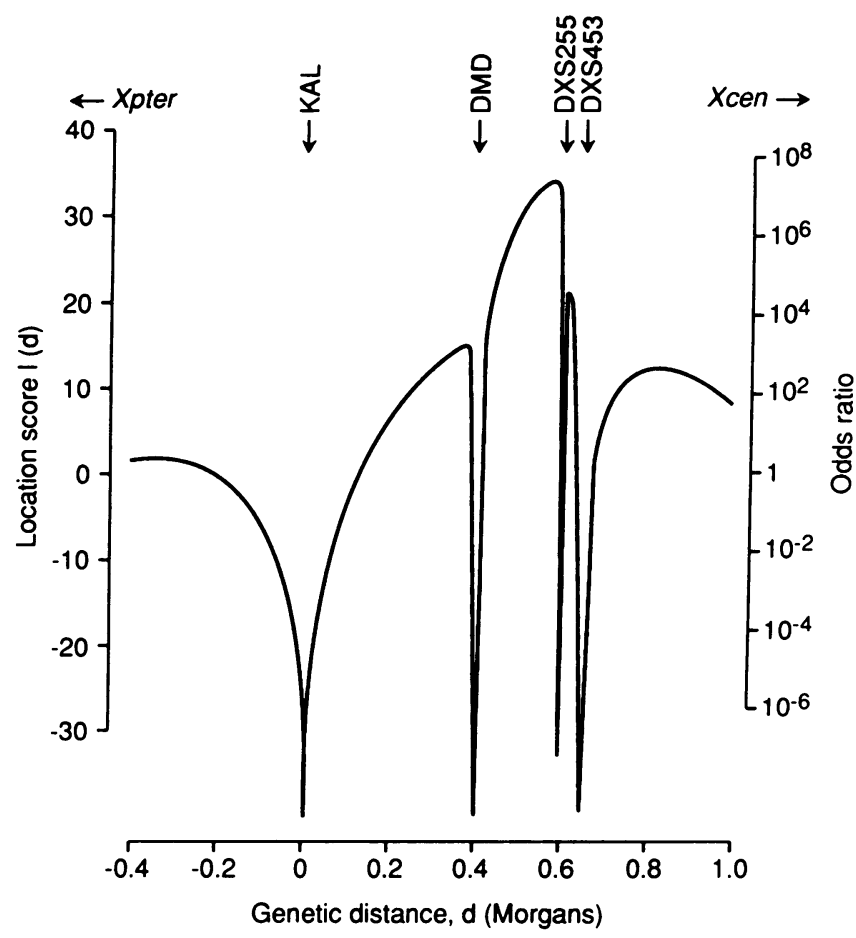

Figure 3. Location scores of $X R N$ versus $X$ chromosome short arm loci KAL, DMD, DXS255, and DXS453. The horizontal axis is the genetic distance (d) in Morgans from the KAL locus which is the arbitrary origin. The right vertical axis is the odds ratio for the location of XRN at a given distance compared with a location of XRN at an infinite distance from the four fixed markers. The left axis is the location score 1 (d), defined as twice the natural logarithm of the odds ratio. A location of XRN between DMD and DXS255 was favored over all the other locations (see Table III).

males locate XRN distal to DXS453 and proximal to DMD, i.e., in the vicinity of DXS255. Recombinants between XRN and DXS255 were not observed in any affected males or carrier females. Examination of individual V.4, who is 28 y old and who has none of the abnormalities of XRN, revealed the presence of the affected haplotype $(1,6,1,3)$ defined, respectively, by the polymorphic loci KAL, DMD, DXS255, and DXS453. The occurrence of such an affected haplotype in this unaffected son (V.4) of an unaffected female (IV.5), who is the daughter of a carrier female (III.6) but has not given birth to any affected children, indicated recombination between XRN and the short arm loci. For example, an analysis of the genotype of the mother IV.5 reveals a double recombination between the Xp marker loci DMD and KAL and between DMD and DXS255, and an analysis of the genotype of the son V.4 reveals a further recombination between DMD and DXS255. Recombinants between the loci DXS255 and DXS453 were not observed in III.6, IV.5, or V.4, and a location of the mutant XRN gene in the genetically small interval between DXS255 and DXS453 in these unaffected individuals from three generations is unlikely. However, the alternative location of XRN in the genetically larger interval between DXS255 and DMD with recombination involving the mutant XRN locus is feasible. Thus, crossovers occurring proximal to the mutant XRN locus in the double recombinant of the mother IV.5 or the single recombinant of the son V.4 would result in an inheritance of the normal gene and an unaffected phenotype. The combined results of these multipoint crossovers suggest a location of XRN between DMD and DXS255.

The likelihood of each of the possible locations of XRN within the fixed order Xpter-KAL-DMD-DXS255-DXS453Xcen was quantitatively assessed using the LINKMAP program. Analysis using the LINKMAP program yielded the location score curve shown in Fig. 3. There is a high peak distal to the DXS255 locus and proximal to the DMD locus, maximum location score $=33.78,0.031$ Morgans distal to the DXS255 locus. There are four subsidiary peaks between Xcen and DXS453, between DXS453 and DXS255, between DMD and $\mathrm{KAL}$, and between KAL and Xpter. The location score for each peak is 12.41 at 0.150 Morgans proximal to DXS453, 21.37 at 0.010 Morgans proximal to DXS255, 15.14 at 0.143 Morgans distal to DMD, and 2.17 at 0.350 Morgans distal to KAL. The odds ratio for a location of XRN in each one of these segments is shown in Table III. This reveals that the odds ratio favoring the order Xpter-KAL-DMD-XRN-DXS255DXS453-Xcen versus a location of XRN unlinked to this cluster of four loci is $>21.6$ million: 1 . In addition, the odds ratio favoring two other locations of XRN within the framework of the four loci are also significant. The odds ratio for a location of XRN distal to DMD and proximal to KAL is $1,900: 1$ and the odds ratio for a location of XRN proximal to DXS255 and distal to DXS453 is $43,700: 1$. Thus, a proximal as opposed to distal location of XRN to DMD is 11,000 times (i.e., 21.6 million $\div 1,900$ ) more likely, and a distal as opposed to proximal location of XRN to DXS255 is 495 times (i.e., 21.6 million $\div 43,700$ ) more likely. These results indicate that XRN maps between DMD and DXS255. All the other odds ratios for possible locations of XRN within this framework of loci are $<1,000: 1$. These results of multipoint linkage analysis demonstrate that the most likely order of genetic loci is Xpter-KALDMD-XRN-DXS255-DXS453-Xcen.

\section{Discussion}

Our linkage study of XRN using 17 polymorphic markers to explore $\mathrm{X}$ chromosome recombination has established linkage between XRN and the DXS255 locus defined by the polymor-

Table III. Order of Genetic Loci and Their Respective Odds Ratios as Calculated from the Location Score Curve in Fig. 3

\begin{tabular}{crr} 
Locus order & Peak location score & Odds ratio \\
\hline Xpter - XRN - KAL - DMD - DXS255 - DXS453 - Xcen & 2.17 & 3 \\
Xpter - KAL - XRN - DMD - DXS255 - DXS453 - Xcen & 15.14 & 1,900 \\
Xpter - KAL - DMD - XRN - DXS255 - DXS453 - Xcen & 33.78 & $21,638,800$ \\
Xpter - KAL - DMD - DXS255 - XRN - DXS453 - Xcen & 21.37 & 43,700 \\
Xpter - KAL - DMD - DXS255 - DXS453 - XRN - Xcen & 12.41 & 500 \\
\hline
\end{tabular}


phic marker $\mathrm{M} 27 \beta$, with the probability in favor of linkage $>812,000: 1$. The genetic marker M27 $\beta$ has previously been localized by somatic cell hybrid, in situ hybridization, and linkage studies to Xp11.22 (30, 32, 34). Thus, the results of our study demonstrating linkage between the disease gene and this genetic marker maps XRN to the pericentromeric region of the short arm of the $\mathrm{X}$ chromosome.

Analysis of the multipoint crosses observed on the short arm of the X chromosome in the family with XRN suggests that XRN maps between the DXS255 and DMD loci. The LINKMAP program is able to use information from a number of multipoint crosses to calculate the most likely location of one unmapped gene in a framework of well mapped markers (27). Within the order Xpter-KAL-DMD-DXS255-DXS453Xcen, a location of XRN between DXS255 and DMD was favored above all other locations (Table III). The odds favoring the location of XRN distal to DXS255 are 495:1 and those favoring a location proximal to DMD are 11,000:1. The genetic distance between DMD and DXS255 has been estimated to be $\sim 20$ centiMorgans $(30,32)$ and an examination of the known cloned and mapped genes (33) to this region of $\mathrm{Xp}$ has not revealed a potential candidate gene for XRN. The additional polymorphic markers DXS84 and OTC (Fig. 2) were therefore utilized to define a more precise genetic map around XRN. The family proved uninformative for these two loci and the map location of XRN could not be defined further. However, our mapping of XRN to this chromosomal segment has identified the region which needs to be investigated further by the use of other polymorphic genetic markers.

The mapping of XRN to Xp1 1.22 demonstrates that a mutation at a locus distant from the Lowe's oculocerebrorenal (OCRL) syndrome and the Alport's syndrome gene is involved in altering renal tubular function and in renal failure. The OCRL gene, which is associated with renal tubular dysfunction and the Fanconi syndrome, has been mapped to Xq25-q26 (4), and the gene for Alport's syndrome, which is associated with nephritis and renal failure, has been mapped to Xq22 (7). In addition, cloning and characterization of the OCRL gene has revealed that the gene encodes a protein with homology to human inositol polyphosphate-5-phosphatase and that the disorder may be due to an inborn error of inositol phosphate metabolism (35). Investigations of patients with the $\mathrm{X}$-linked form of Alport's syndrome have revealed mutations in the collagen type IV alpha 5 (COL4A5) gene (36). XRN, which maps to $\mathrm{Xp1} 1.22$, is thus genetically and clinically a separate entity from the other two reported $\mathrm{X}$-linked renal disorders. $\mathrm{XRN}$ is associated with the Fanconi syndrome, and a possible role for an inborn error in inositol phosphate metabolism similar to that for OCRL needs to be elucidated. The precise mapping of the XRN gene to Xp11.22 by our linkage study represents an important step towards understanding the role of this gene in regulating renal tubular function and in identifying the metabolic defect. Our localization of this mutant gene identifies the chromosomal segment in which a concentrated search for deletions and closer genetic markers is required to further elucidate the factors controlling renal tubular transport and the precipitation of renal calculi.

\section{Acknowledgments}

We are grateful to the Medical Research Council (MRC) (UK) and to Dialysis Clinics, Inc. (USA) for support; to Dr. I. W. Craig, Dr. K. E.
Davies, Dr. R. Lofthouse, Dr. M. Poulter, and Dr. T. Shah for the gift of probes and primers; to the MRC Human Genome Mapping Project (UK) for primers; to D. S. Patchin and B. Harding for assistance with the collection and handling of blood specimens; to Dr. K. E. Davies, Dr. D. Porteous, Dr. S. Povey, and Dr. V. van Heyningen for the gift of rodent-human somatic cell hybrids; to F. R. Rysavy at the Division of Computer Services, MRC Clinical Research Centre, for making available the computing facilities; and to L. Sargeant for typing the manuscript. Dr. S. J. Scheinman was on sabbatical leave from the State University of New York Health Science Center to the Royal Postgraduate Medical School (UK) during the period of these studies.

\section{References}

1. Frymoyer, P. A., S. J. Scheinman, P. B. Dunham, D. B. Jones, P. Hueber, and E. T. Schroeder. 1991. X-linked recessive nephrolithiasis with renal failure. N. Engl. J. Med. 325:681-686.

2. McCune, D. J., H. H. Mason, and H. T. Clarke. 1943. Intractable hypophosphatemic rickets with renal glycosuria and acidosis ( the Fanconi syndrome): report of a case in which increased urinary organic acids were detected and identified, with a review of the literature. Am. J. Dis. Child. 65:81-89.

3. Lowe, C. U., M. Terrey, and E. A. MacLachlan. 1952. Organic-aciduria, decreased renal ammonia production, hydrophthalmos and mental retardation. Am. J. Dis. Child. 83:164-168.

4. Silver, D. N., R. A. Lewis, and R. L. Nussbaum. 1987. Mapping the Lowe oculo-cerebro-renal syndrome to Xq24-q26 by use of restriction fragment length polymorphisms. J. Clin. Invest. 79:282-285.

5. Thakker, R. V., and J. L. H. O'Riordan. 1988. Inherited forms of rickets and osteomalacia. In Clinical Endocrinology and Metabolism. Vol. 2, No. 1. Metabolic Bone Disease. T. J. Martin, editor. Balliere Tindall Ltd., London. 157-191.

6. Alport, A. C. 1927. Hereditary familial congenital haemorrhagic nephritis. Br. Med. J. 1:504-506.

7. Atkin, C. L., S. J. Hasstedt, L. Menlove, L. Cannor, N. Kirschner, C. Schwartz, J. Nguyen, and M. Skolnick. 1988. Mapping of Alport syndrome to the long arm of the X chromosome. Am. J. Hum. Genet. 42:249-255.

8. Weber, J. L., and P. E. May. 1989. Abundant class of human DNA polymorphisms which can be typed using the polymerase chain reaction. Am. J. Hum. Genet. 44:388-396.

9. Litt, M., and J. A. Luty. 1989. A hypervariable microsatellite revealed by in vitro amplification of a dinucleotide repeat within the cardiac muscle actin gene. Am. J. Hum. Genet. 44:397-401.

10. Kunkel, L. M., K. D. Smith, S. H. Boyer, D. S. Borgaonkar, S. S. Wachtel, O. J. Miller, W. R. Breg, H. W. Jones, and J. M. Rary. 1977. Analysis of human Y chromosome specific reiterated DNA in chromosome variants. Proc. Natl. Acad. Sci. USA. 74:1245-1249.

11. Southern, E. M. 1975. Detection of specific sequences among DNA fragments separated by gel electrophoresis. J. Mol. Biol. 98:503-517.

12. Thakker, R. V., P. Bouloux, C. Wooding, K. Chotai, P. M. Broad, N. K. Spurr, G. M. Besser, and J. L. H. O'Riordan. 1989. Association of parathyroid tumors in multiple endocrine neoplasia type 1 with loss of alleles on chromosome 11. N. Engl. J. Med. 321:218-224.

13. Feinberg, A. P., and B. Vogelstein. 1983. A technique for radiolabelling DNA restriction endonuclease fragments to high specific activity. Anal. Biochem. 132:6-13.

14. Bouloux, P.-M. G., J.-P. Hardelin, P. Munroe, J. M. W. Kirk, R. Legouis, J. Levilliers, J. Hazan, J. Weissenbach, and C. Petit. 1991. A dinucleotide repeat polymorphism at the Kallmann locus (Xp22.3). Nucleic Acids Res. 19:5453.

15. Clemens, P. R., R. G. Fenwick, J. S. Chamberlain, R. A. Gibbs, M. de Andrade, R. Chakraborty, and C. T. Caskey. 1991. Carrier detection and prenatal diagnosis in Duchenne and Becker muscular dystrophy families, using dinucleotide repeat polymorphisms. Am. J. Hum. Genet. 49:951-960.

16. Weber, J. L., A. E. Kwitek, P. E. May, M. H. Polymeropoulos, and S. Ledbetter. 1990. Dinucleotide repeat polymorphisms at the DXS453, DXS454 and DXS458 loci. Nucleic Acids Res. 18:4037.

17. Stanier, P., R. Newton, S. A. Forbes, A. Ivens, and G. E. Moore. 1991. Polymorphic dinucleotide repeat at the DXS53 locus. Nucleic Acids Res. 19:4793.

18. Luty, J. A., Z. Guo, H. F. Willard, D. H. Ledbetter, S. Ledbetter, and M. Litt. 1990. Five polymorphic microsatellite VNTRs on the human X chromosome. Am. J. Hum. Genet. 46:776-783.

19. Luty, J. A., H. F. Willard, and M. Litt. 1989. Three new microsatellite VNTRs on the X chromosome. Cytogenet. Cell Genet. 51:1036.

20. Hearne, C. M., and J. A. Todd. 1991. Tetranucleotide repeat polymorphism at the HPRT locus. Nucleic Acids Res. 19:5450.

21. Nabholz, M., V. Miggiano, and W. Bodmer. 1969. Genetic analysis with human-mouse somatic cell hybrids. Nature (Lond.). 223:358-363.

22. Porteous, D. J., J. E. N. Morten, G. Cranston, J. M. Fletcher, A. Mitchell, 
V. Van Heyningen, J. A. Fantes, P. A. Boyd, and N. D. Hastie. 1986. Molecular and physical arrangements of human DNA in HRASI-selected, chromosomemediated transfectants. Mol. Cell. Biol. 6:2223-2232.

23. Wieacker, P., K. E. Davies, H. J. Cooke, P. L. Pearson, R. Williamson, S. Bhattacharya, J. Zimmer, and H. H. Ropers. 1984. Towards a complete linkage map of the human $\mathrm{X}$ chromosome: regional assignment of 17 cloned single copy DNA sequences employing a panel of somatic cell hybrids. Am. J. Hum. Genet. 36:265-276.

24. Ingle, C., R. Williamson, A. de la Chappelle, R. R. Herva, K. Haapala, G. Bates, H. F. Willard, P. Pearson, and K. E. Davies. 1985. Mapping DNA sequences in a human $\mathrm{X}$ chromosome deletion which extends across the region of the Duchenne muscular dystrophy mutation. Am. J. Hum. Genet. 37:451-462.

25. Mohandas, T., R. S. Sparkes, B. Hellkuhl, K. H. Grzeschik, and L. J. Shapiro. 1980. Expression of an X-linked gene from an inactive human $\mathrm{X}$ chromosome in mouse-human hybrid cells: further evidence for the non-inactivation of the steroid sulphatase locus in man. Proc. Natl. Acad. Sci. USA. 77:6759-6763.

26. Lathrop, G. M., and J. M. Lalouel. 1984. Easy calculation of LOD scores and genetic risks on small computers. Am. J. Hum. Genet. 36:460-465.

27. Lathrop, G. M., J. M. Lalouel, C. Julier, and J. Ott. 1984. Strategies for multi-locus linkage analysis in humans. Proc. Natl. Acad. Sci. USA. 81:34433446.

28. Thakker, R. V., K. E. Davies, M. P. Whyte, C. Wooding, and J. L. H. O'Riordan. 1990. Mapping the gene causing X-linked recessive idiopathic hypoparathyroidism to Xq26-Xq27 by linkage studies. J. Clin. Invest. 86:40-45.

29. Drayna, D., and R. White. 1985 . The genetic linkage map of the human X-chromosome. Science (Wash. DC). 230:753-758.
30. Kirchgessner, C. U., J. A. Trofatter, M. M. Mahtani, H. F. Willard, and L. J. DeGennaro. 1991. A highly polymorphic dinucleotide repeat on the proximal short arm of the human X chromosome: linkage mapping of the synapsin I/A-raf-I genes. Am. J. Hum. Genet. 49:184-191.

31. Lindsay, S., D. L. Thiselton, J. B. Bateman, J. T. Ngo, R. S. Sparkes, M. Coleman, K. E. Davies, and S. S. Bhattacharya. 1992. Localization of the gene for Norrie disease to between DXS7 and DXS426 on Xp. Hum. Genet. 88:349-350.

32. Davies, K. E., J.-L. Mandel, A. P. Monaco, R. L. Nussbaum, and H. F. Willard. 1991. Report of the committee on the genetic constitution of the $\mathrm{X}$ chromosome. Cytogenet. Cell Genet. 58:853-966.

33. Williamson, R., A. Bowcock, K. Kidd, P. Pearson, J. Schmidtke, P. Ceverha, M. Chipperfield, D. N. Cooper, C. Coutelle, J. Hewitt, et al. 1991. Report of the DNA Committee and catalogues of cloned and mapped genes, markers formulated for PCR and DNA polymorphisms. Cytogenet. Cell Genet. 58:11901832.

34. Fraser, N. J., Y. Boyd, G. G. Brownlee, and I. W. Craig. 1987. Multi-allelic RFLP for M27 $\beta$, an anonymous single copy genomic clone at Xp11.3-Xcen (HGM9 provisional no. DXS255). Nucleic Acids Res. 15:9616.

35. Attree, O., I. M. Olivos, I. Okabe, L. C. Bailey, D. L. Nelson, R. A. Lewis, R. R. McInnes, and R. L. Nussbaum. 1992. The Lowe's oculocerebrorenal syndrome gene encodes a protein highly homologous to inositol polyphosphate-5phosphatase. Nature (Lond.). 358:239-242.

36. Barker, D. F., S. L. Hostikka, J. Zhou, L. T. Chow, A. R. Oliphant, S. C. Gerken, M. C. Gregory, M. H. Skolnick, C. L. Atkin, and K. Tryggvason. 1990 Identification of mutations in the COL4A5 collagen gene in Alport syndrome. Science (Wash. DC). 248:1224-1227. 